\title{
A Review of Os Odontoideum in Children
}

\section{Elvira A Allakhverdieva ${ }^{1}$, Ryan A Grant ${ }^{2}$ and Michael Diluna ${ }^{2 *}$}

${ }^{1}$ Frank H. Netter M.D. School of Medicine at Quinnipiac University, North Haven, CT, USA

${ }^{2}$ Yale University School of Medicine, Department of Neurosurgery, New Haven, CT, USA

\begin{abstract}
Study Background: Os odontoideum is an anomaly of the cervical axis characterized by an independent ossicle of variable size separated from the hypoplastic dens that can present as an incidental radiographic finding to severe neck pain, torticollis, myelopathy, as well as seizures and syncope. Diagnosis is primarily made based on clinical presentation and extensive radiologic evaluation. In this review, we discuss the etiology, treatment, and management of this rare condition in the pediatric population and propose a treatment algorithm.
\end{abstract}

Methods: We performed a comprehensive retrospective review of English literature in PubMed on surgical approaches to treatment and stabilization of Os osontoideum in children.

Results: Asymptomatic children, who are diagnosed with Os odontoideum, but lack overt neurologic deficits, are advised to continue radiologic monitoring with lateral flexion-extension X-rays once a year and MRI evaluation once every five years. For symptomatic patients with significant atlantoaxial instability, neurologic deficits, or myelopathy, surgical treatment is recommended. In cases where the atlantoaxial joint is aligned properly without any kyphotic deformities and vertebral arteries abnormalities, transarticular C1-C2 screw fixation should be considered. If these requirements are not met, $\mathrm{C} 1$ lateral mass screws with $\mathrm{C} 2$ pars/pedicle screws method are advised. The transoral approach, odontoid screw fixation, and minimally invasive techniques are possible alternatives, but have not been studied enough to be considered standard treatments in pediatric population.

Conclusions: These recommendations are meant to initiate a "best practices" strategy for treatment of Os odontoideum in children. We anticipate further refinement of these recommendations as new research and reports arise in the field of minimally invasive neurosurgery.

Keywords: Os odontoideum; Atlantoaxial instability; C1-C2 instability; Atlantoaxial fusion

\section{Introduction}

Os odontoideum is an anomaly of the cervical axis characterized by an independent ossicle of variable size separated from the hypoplastic dens [1]. This lesion was first described by C. Giacomini in 1886 as an incompetent odontoid process associated with craniovertebral junction instability [2]. Anatomically, it can be subdivided into orthotopic and dystopic types. An orthotopic ossicle is located in a normal position, posteriorly to the anterior arch of $\mathrm{C} 1$, whereas a dystopic ossicle is fixed in a displaced position and often fused with the basion. The gap between the small dens and free ossicle usually extends above the superior facets of the axis [1]. Os odontoideum needs to be differentiated from a persistent ossiculum terminale or a type II odontoid fracture. The former entity represents failure of fusion of the secondary ossification center and is thought to be a normal anatomical variant [1]. Radiographically, Os odontoideum appears as a smooth, well corticated independent ossicle with sclerotic margins. Alternatively, dens fractures appear as sharp, non-corticated structures with irregular margins [3].

The odontoid process is an important structure of the cervical spine, helping connect the skull to the neck, maintaining atlantoaxial stability, as well as allowing for the majority of head rotation. More specifically, atlantoaxial articulation accounts for 50 of 100 degrees of rotation and 10 of 110 degrees of flexion/extension of the cervical spine. In the presence of an abnormal dens configuration or a nonstructural position of an aberrant ossicle, incompetence of the cruciate ligament can occur and subsequently lead to atlantoaxial instability [4]. Additionally, translocation of the ossicle can result in cervicomedullary and vertebral artery compression, potentially leading to stroke [5]. In terms of presentation, the condition can vary from an incidental radiographic finding in an asymptomatic patient to severe neck pain, torticollis, myelopathy, as well as seizures and syncope [6].

The age of diagnosis varies from the first to the sixth decades of life, with increased frequency in patients with multiple epiphyseal dysplasia, Down syndrome, and Klippel-Feil syndrome [7,8]. Despite numerous cases of Os odontoideum being reported, the exact incidence and prevalence of this condition in the pediatric population remains unknown. Based on a retrospective study of abnormal cervical spine scans of 519 pediatric patients performed between 1991 and 2004 at the Children `s Hospital of Philadelphia, the predicted prevalence rate is approximately $3.1 \%$ [7]. Nevertheless, persistent symptoms and cervical imaging can help establish this rare diagnosis. In this review, we discuss embryology, etiology, clinical presentation, workup, management, and treatment of Os odontoideum in the pediatric population.

\section{Embryology and Etiology}

The atlas and the axis are two unique and complex embryologic structures whose development relies on differentiation of the cervical and spinal sclerotomes [9-11]. More specifically, the fourth occipital sclerotome (proatlas) forms the superior aspect of the posterior atlas ring and apex of the dens. The first cervical sclerotome forms the inferior aspect of the posterior atlas ring, anterior arch of the atlas, and the dens, whereas the second cervical sclerotome forms the body of the axis [911]. The dens are separated from the base of the axis by a synchondrosis - a cartilaginous band - that typically fuses by the age of 3 [10]. At the same time the tip of the dens, called the ossiculum terminale, begins to

*Corresponding author: Michael Diluna, M.D., Department of Neurosurgery, Yale-New Haven Hospital, New Haven, CT, USA, Tel: 203-737-2096; E-mail: michael.diluna@yale.edu

Received November 30, 2015; Accepted December 10, 2015; Published December 12, 2015

Citation: Allakhverdieva EA, Grant RA, Diluna M (2015) A Review of Os Odontoideum in Children. J Spine 4: 270.doi:10.4172/2165-7939.1000270

Copyright: (C) 2015 Allakhverdieva EA, et al. This is an open-access article distributed under the terms of the Creative Commons Attribution License, which permits unrestricted use, distribution, and reproduction in any medium, provided the original author and source are credited. 
appear visible on X-rays. It usually fuses with the dens by the age of 12 at the secondary ossification center [10]. Additionally, the blood supply of the axis is also quite complicated: the base of the axis is supplied by the ascending branches of the vertebral arteries, while the dens is supplied by the descending branches of the internal carotid arteries, forming a watershed area between these two structures, which may lead to necrosis between the forming entities and in turn a non-fused ossicle.

The etiology of Os odontoideum remains controversial. Initially, Os odontoideum was thought to be just a congenital fusion failure of the dens to the remainder of the axis (Figure 1), but that is now recognized as a clearly separate entity known as ossiculum terminale [12]. Differentiation between Os odontodieum and a persistent ossiculum terminale is clinically important because the latter is not associated with significant instability. To date, the etiology of Os odontoideum has two main theories: congenital and acquired, whereas some authorities advocating for a multifactorial origin [9]. The cornerstones of the congenital theory resonate on a failure of sclerotome migration, failure of fusion at the central synchodrosis or secondary ossification center, and non-traumatic avascular necrosis at the watershed area [9]. This theory is supported by several case reports and twin studies that demonstrate an autosomal dominant pattern of inheritance $[13,14]$. The higher incidence of Os odontoideum is reported among patients with congenital syndromes such as multiple epiphyseal dysplasia, Down syndrome, and Klippel-Feil syndrome [13-15]. Nevertheless, these congenital conditions can be linked to increased ligamental hyperlaxity and incomplete ossification of the odontoid process, as well as be associated with increased risk for traumatic injury of the dens [1]. On the other hand, the acquired theory suggests that development of Os odontoideum is followed by unrecognized trauma and subsequent osseous remodeling before the closure of the synchondrosis [1618]. Several authors report cases of patients with post-traumatic Os odontoideum with previously normal radiographs [19-21]. In this model, following a fracture at the odontoid synchondrosis, Os odontoideum develops gradually as the growing alar ligaments carry the ossicle away from the base of the axis (Figure 1). The cranial portion of the fragment continues to be vascularized, but the caudal portion resorbs from a lack of blood supply resulting in a stereotypical rounded ossicle [19-21]. Other models in the acquired realm include excessive movement at the time of ossification of the cartilaginous dens [1]. Although most literature favors the post-traumatic theory, the etiology of os odontoideum most likely is multifactorial, encompassing congenital, traumatic, genetic, and environmental factors.

\section{Clinical Presentation and Natural History}

Regardless of what causes the formation of Os odontoideum, understanding the natural history and potential clinical symptomatology is paramount. The clinical presentation can range from occipitocervical pain, local mechanical neck pain, torticollis, headache, myelopathy, and/or neurovascular compromise including vertebrobasilar ischemia
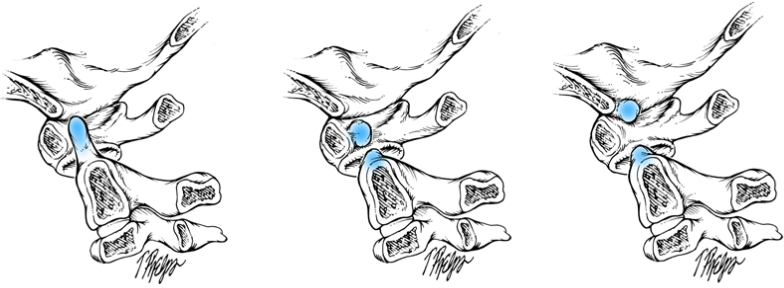

Figure 1: Artist illustration demonstrating the development of Os odontoideum (shaded blue area). Two theories exist including congenital and acquired, with the likely etiology of a multifactorial origin.

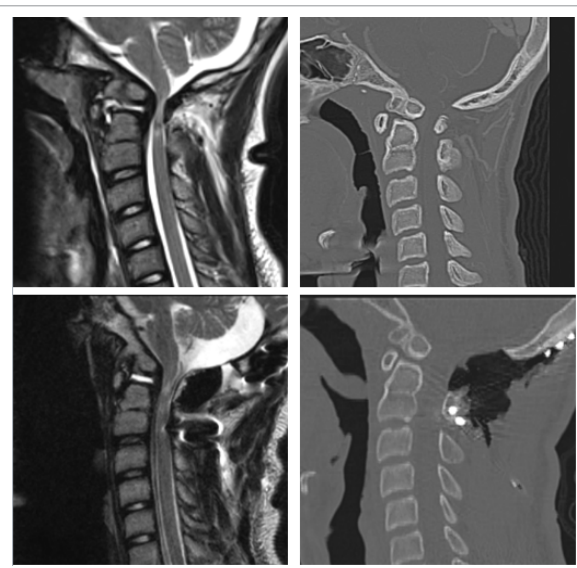

Figure 2: Steretypical imaging of Os odontoideum with CT on the left and MRI on the right.

[6]. In patients with cervical instability, hypermobility of $\mathrm{C} 1$ on $\mathrm{C} 2$ can lead to direct cervicomedullary compression or blood supply compression leading to neurological symptoms. Depending on the type of compression, neurological symptoms can be transient or develop into a chronic diffuse paresis secondary to a progressive myelopathy and even go on to complete spinal cord injury [22]. In some cases, the diagnosis of Os odontoideum is made as the result of incidental radiologic findings. In others, recent or long-time unnoticed cervical spine trauma leads to neurologic deficits and subsequent Os odontoideum development.

Symptoms develop because of the abnormal movement of the bony structures. In a subset of patients, the secondary ligaments become lax, resulting in excessive anterior movement of the atlas on the axis [23]. As with most mechanical systems, longstanding instability results in development of multidirectional movement, increasing the risk of potential complications. Subluxation and instability are possible for both the orthotopic and dystopic forms of Os odontoideum; though some believe that the latter is more likely to be symptomatic [1]. Unfortunately, how many patients will become symptomatic is unknown

\section{Work-up and Diagnostic Imaging}

The diagnosis of Os odontoideum is made based on the clinical presentation and radiologic evaluation of the patient. Plain X-rays of the spine with anterioposterior and open-mouth odontoid views are the current recommendation and most often are sufficient enough to establish the diagnosis [24]. The dynamic lateral X-rays with flexionextension views can provide additional information about motion abnormalities and atlantoaxial instability. However, this modality should be used only if stability of the cervical spine is not compromised $[1,24]$. Computed tomography (CT) and magnetic resonance imaging (MRI) may be considered to assess craniocervical junction deficits (Figure 2).

Atlantoaxial instability is the major determining factor in management of the patients with Os odontoideum. There are three main radiologic modalities that are used for assessment of the degree of instability: the arch-peg ratio, space available for the spinal cord (SAC), and the instability index [25]. The arch-peg ratio is measured on a sagittal CT and is used to quantify anterior arch hypertrophy, with an elevated arch-peg ratio signifying longstanding atlantoaxial joint instability [25]. The SAC is the measurement useful in assessment and management of myelopathy due to spinal cord compression. A SAC 
of $13 \mathrm{~mm}$ or less is considered significant; however, due to individual variations this measurement is not a very reliable predictor of joint instability [26,27]. Lastly, the instability index measures the dynamic sagittal diameter of the spinal canal. The probability of neurological symptoms/signs significantly increases with an instability index over $40 \%$ [28].

More specifically, the first step of radiologic evaluation of OS odontoideum is to obtain anterior-posterior and open-mouth X-rays of the cervical spine. Os odontoineum appears as a smooth ossicle with a uniform cortex separated from the base of the axis with a wide gap (Figure 2). Of note, the gap lies above the level of the superior articular facets. The shape of the ossicle can range from round to oval to toothshaped [29] and the hypoplastic dens of the axis is almost always present [10]. The orthotopic os odontoideum is located in normal anatomical position and can be confused with nonfused synchondrosis, odontoid hypoplasia, or an odontoid fracture nonunion in children under the age of 3, as the neurocentral synchondrosis has not yet fused [3]. Dynamic lateral films can be obtained in this situation, as the presence of significant movement is seen in patients with Os odontoideum and absence of movement is seen in young patients with nonfused synchodrosis. The open-mouth odontoid X-rays are also very useful in distinguishing Os odontoideum from type II odontoid fractures. In fracture cases, the dens will appear to have a normal shape, with a very narrow gap between the base and the dens. Lastly, the diagnosis of dystopic os odontoineum is more straightforward, as radiographically, the dystopic ossicle is located in a nonanatomical position, such as fused to the clivus or to the anterior ring of the atlas [10].

For the evaluation of atlantoaxial instability in symptomatic patients, flexion-extension dynamic X-rays of the cervical spine are an important part of the evaluation. However, caution should be exercised in pediatric and trauma patients, given the potential to induce neurological damage. A predictor for the risk of development of spinal cord compromise and atlantoaxial instability is the anterior atlantodental interval (AADI). This is measured as the distance between the posterior cortex of the anterior arch of $\mathrm{C} 1$ and the anterior cortex of the dens, with the cutoff value greater than $3 \mathrm{~mm}$ in older children and $4 \mathrm{~mm}$ in younger children $[3,24,30]$. However, some authors believe that the AADI does not reflect the abnormal motion of the ossicle since this fragment often moves together with the atlas [31]. Similarly, a SAC of more than $13 \mathrm{~mm}$ in older children is predictive of instability [32].

As expected, more detailed information about atlantoaxial joint structure is provided with a sagittally reconstructed CT. CT images give more precise representation of the cervical spine structures, which helps to assess the probability of the development of the neurological symptoms in asymptomatic patients and evaluate the severity of the condition in symptomatic patients. The above mentioned SAC measurement is now substituted with the posterior atlantodental interval (PADI) - the distance between the posterior border of the dens and the anterior border of the posterior ring of the atlas on CT [24]. PADI has the same value as SAC with a cutoff value at $13 \mathrm{~mm}$, but provides a more precise assessment of the actual space for the spinal cord [24]. A CT angiogram should also be considered to assess the vasculature, particularly the vertebral arteries. Finally, in symptomatic patients, who present with neurologic symptoms, T1/T2-weighted and STIR MRI imaging can be used to identify edema, myelomalacia, ligament integrity, fracture age, as well as necrosis and/or hemorrhage of the spinal cord. Taking the current literature into account, we have provided an algorithm for the recommended radiologic evaluation sequence in Figure 3.

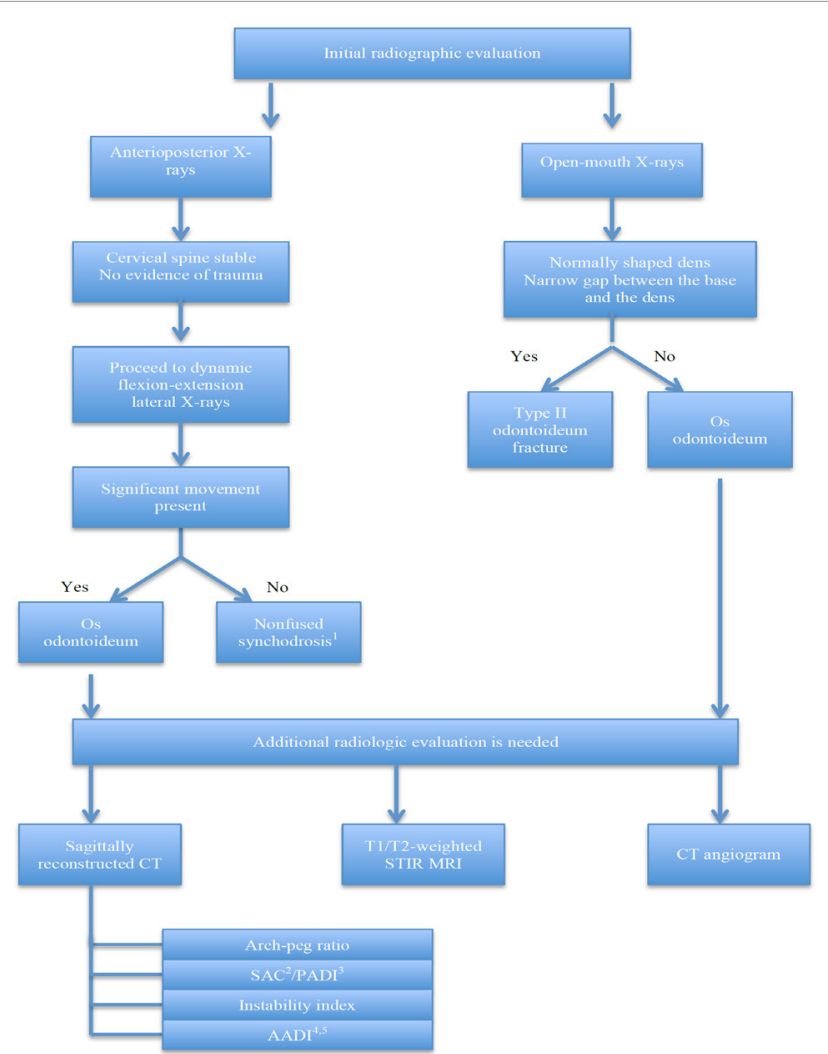

${ }^{1}$ Applies to children under 3 years of age, who still might have unfused neurocentral synchondrosis. ${ }^{2}$ Space available for spinal cord. ${ }^{3}$ Posterior atlantodental interval. ${ }^{4}$ Atlantodens interval. ${ }^{5}$ The accuracy and usefulness of ADI is still a debatable topic.

Figure 3: Algorithm for the radiologic evaluation of Os odontoideum in children.

\section{Management}

Optimal management of Os odontoideum remains a debated topic in the field of neurosurgery. Not only does the exact etiology remain questionable, there are no strict guidelines for its treatment and management. Nevertheless, below we review the current available literature regarding the management and treatment of os odontoideum in the pediatric population.

Minimally symptomatic or asymptomatic patients without atlantoaxial instability can be managed with conservative methods. It is worth noting that extensive radiologic evaluation of $\mathrm{C} 1-\mathrm{C} 2$ cervical stability is necessary to make this conclusion. The observation may include long-term clinical and radiographic surveillance. Arvin et al. strongly suggests yearly follow up with flexion-extension $\mathrm{x}$-rays and MRI of the craniocervical junction every 5 years to eliminate the potential risk for spinal cord compression [1]. Additionally, patients may be advised against participation in contact sports [1]. Asymptomatic patients are more difficult to manage, as currently, there is no sufficient evidence to predict the future development of myelopathy or other spinal cord deficits. Regardless, each patient must be evaluated on an individual basis, taking into account the benefits of the surgery and the potential complications of nonsurgical treatment.

The recommendations for symptomatic patients with Os odontoideum are more standardized. The goal of surgical intervention in symptomatic patients is to regain cervical spine stability. The surgical techniques for Os odontoideum treatment in pediatric population have evolved during the past several decades, but upper cervical vertebral 
fusion remains the main surgical goal. Children who have neurologic deficits and/or C1-C2 instability can be offered a number of surgical options. The earliest technique used for treatment of Os odontoideum was posterior atlantoaxial fixation with onlay autologous bone fusion. However, high pseudoarthrosis rates and prolonged external immobilization with a halo or Minerva brace made this approach unpopular [33]. As the result, it was improved upon and substituted with posterior atlantoaxial wiring and fusion, including Gallie, Kirschner, and Brooks types [33]. The Gallie type involved placement of four twisted wires under the posterior $\mathrm{C} 1$ ring and around the $\mathrm{C} 2$ spinous process. The Gallie type was only plausible to use in older children with an ossified C2 spinous process. In younger patients, this technique evolved into the Kirschner type, which involved the placement of a K-wire through the $\mathrm{C} 2$ spinous process for better stabilization [33]. The more advanced technique was the Brooks approach, which involved passing 4 wires under the $\mathrm{C} 2$ lamina and $\mathrm{C} 1$ ring. It offered better stabilization of the cervical spine, but was associated with a higher risk of spinal cord injury during wire placement and again prolonged postoperative stabilization was required. This technique was not recommended for young children as the size of spinal canal was too small for safe wire placement [34]. Additionally, the long-term use of halo immobilization has been associated with a risk for pin site infections and the possibility of early removal of the device given children's inability to tolerate the device, leading to failure of the fusion.

In terms of real world results with wiring, Griswold et al. described some of the earliest cases of cervical fusion in 4 children with Os odontoineum in 1978 [35]. Among 4 patients, 3 were successfully treated with sublaminar C1-C2 wire fusion with autologous iliac crest graft. In the fourth patient, the fusion failed after 3 attempts. The procedure involved passing four twisted wires along the posterior undersurfaces of the atlas and axis. The iliac bone grafts were placed between $\mathrm{C} 1$ and C2 lamina to stabilize the wires [35]. At the same time, Brooks et al. also reported 3 pediatric cases of Os odontoideum treated with sublaminar C1-C2 fusion with autologous iliac crest graph technique [36]. All patients were placed in Minerva plaster jackets post-operatively. All fusions were successful with one child having spontaneous extension of fusion to C3 [36]. Dyck et al. used similar surgical technique in treatment of 8 children, 6 had Os odontoideum and 2 required reoperation [37]. $\mathrm{He}$ reported that all patients required postoperative immobilization for
3-4 months [37]. In 1991, Smith et al. conducted a retrospective review of 17 children, among which 11 had Os odontoideum with instability [38]. All patients were treated with posterior fusion of C1-C2. The same techniques of posterior wiring and autologous bone graft were applied. All children wore halo vests post-operatively for stabilization. 9 patients had successful fusion, 2 had nonunion fusion failure, and 1 had spinal cord injury due to sublaminar wire passage [38]. A few years later, Lowry et al. reviewed 11 pediatric patients with Os odontoideum, who underwent the upper cervical spine fusion at Children 's Hospital of Pittsburg in Pennsylvania [39]. 10 children underwent Brooks-type C1C2 fusion and 1 had Gallie-type fusion, which did not fuse and had to be reoperated using Brook's fusion subsequently. All patients also had post-operative halo vest stabilization, except one who had hard collar. In addition to the above mentioned patient, one more patient failed to fuse due to the development of multiple halo pin infections and early removal of the hardware [39]. To date, wiring has mostly fallen out of favor, but is still a robust bailout and supplemental method to screwrod constructions (Table 1 ).

Transarticular C1-C2 screw fixation is one of the newer techniques for the treatment of Os odontoideum today. This approach provides immediate cervical stability in all planes and eliminates the need for halo stabilization [40,41]. Though this approach reaches $98 \%$ fusion rate, it has a large number of limitations for the proper placement of the hardware [42]: misaligned atlantoaxial joints, thoracic kyphotic deformity, as well as vertebral artery and osseous anomalies [1]. The more modern and most utilized method for Os odontoideum treatment in children is a screw-based rigid internal fixation of the cervical spine. This technique was first introduced by Goel and popularized by Harms in 2001 [43]. It involves placement and connection of $\mathrm{C} 1$ lateral mass screws to $\mathrm{C} 2$ pars, $\mathrm{C} 2$ pedicle, or translaminar screws [44]. The C1 lateral mass usually allows for screw placement even in the youngest of the pediatric population. The type of the axial screw depends on the variety of factors such as width of the bony channel and the position of the vertebral arteries [45]. Even though placement of the lateral mass screws might be challenging in patients with vertebral artery variations, spinal cord injury is almost unheard of given the wide diameter of the spinal canal at this level. The wide number of possible variations for screw placement ensures its availability for patients with a significant range of anatomic anomalies. Even more, the transarticular

\begin{tabular}{|c|c|c|c|c|c|}
\hline Year & Author & $\begin{array}{c}\text { No. of } \\
\text { patients }\end{array}$ & Surgical method & Outcome & Stabilization method \\
\hline \multirow[b]{2}{*}{1978} & \multirow[b]{2}{*}{ Griswold et al. } & \multirow[b]{2}{*}{4} & \multirow[b]{2}{*}{ Sublaminar C1-C2 wire fusion with autologous iliac crest graft } & 3 fused & \\
\hline & & & & 1 didn't fuse & \\
\hline 1978 & Brooks et al. & 3 & Sublaminar $\mathrm{C} 1-\mathrm{C} 2$ wire fusion with autologous iliac crest graft & All 3 fused & Minerva cast \\
\hline \multirow[b]{2}{*}{1978} & \multirow[b]{2}{*}{ Dyck et al. } & \multirow[b]{2}{*}{6} & \multirow[b]{2}{*}{ Posterior wiring and fusion of $\mathrm{C} 1-\mathrm{C} 3$} & 4 fused & \multirow{2}{*}{$\begin{array}{l}\text { 3-4ms four-poster } \\
\text { brace immobilization }\end{array}$} \\
\hline & & & & 2 needed reoperation & \\
\hline \multirow[b]{2}{*}{1991} & \multirow[b]{2}{*}{ Smith et al. } & \multirow[b]{2}{*}{11} & \multirow[b]{2}{*}{ Posterior wiring of $\mathrm{C} 1-\mathrm{C} 2$ with autologous bone graft } & 9 fused & \multirow[t]{2}{*}{ HALO } \\
\hline & & & & 2 non-union fusion failure & \\
\hline 1992 & Menezes & 4 & C1-C2 posterior wiring and fusion with autologous rib graft & All fused & HALO for 3months \\
\hline \multirow[b]{2}{*}{1997} & \multirow[b]{2}{*}{ Lowry et al. } & \multirow[b]{2}{*}{11} & \multirow{2}{*}{$\begin{array}{c}10 \text { treated with Brook`s type } \\
\text { fusion } 1 \text { treated with Gallie -type fusion, followed by Brook`s-type } \\
\text { reoperation }\end{array}$} & 1 didn't fuse & \multirow[t]{2}{*}{$10 \mathrm{HALO}$} \\
\hline & & & & $\begin{array}{l}1 \text { didn't fuse with Gallie, } \\
\text { but then fuse with Brooks }\end{array}$ & \\
\hline 1999 & Wang et al. & 4 & $\mathrm{C} 1-\mathrm{C} 2$ transarticular screw and posterior $\mathrm{C} 1-\mathrm{C} 2$ wiring and fusion & All 4 fused & Miami-J collar only \\
\hline 2000 & $\begin{array}{l}\text { Brookmeyer } \\
\text { et al. }\end{array}$ & 12 & Transarticular screw fusion & $\begin{array}{l}\text { All had bilateral screws } \\
\text { placed }\end{array}$ & Not known \\
\hline 2009 & Haque et al. & 5 & Transarticular screw fusion & All fused & \\
\hline 2014 & Zhang et al. & 6 & Posterior fixation and fusion & All fused & Not known \\
\hline
\end{tabular}

Table 1: Management of Os odontoideum in children: surgical and stabilization methods. 


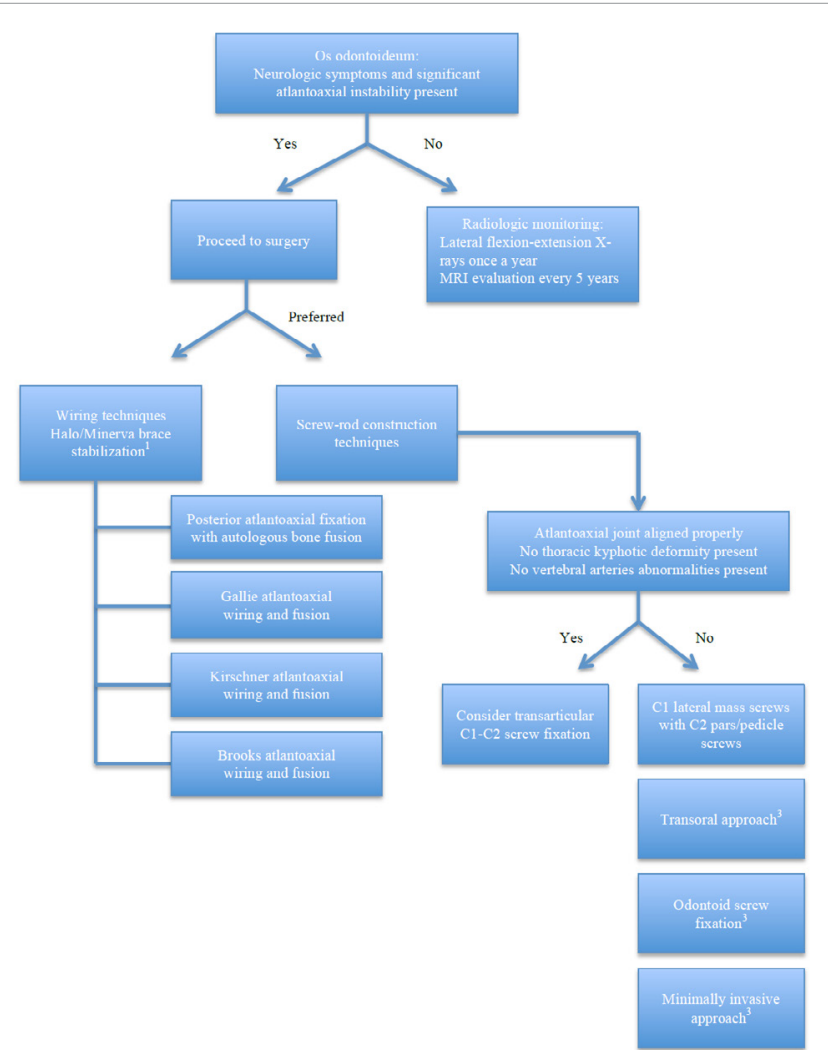

${ }^{1}$ Wiring techniques are rarely used today, except the cases when newer surgical methods cannot be utilized.

${ }^{2}$ Halo vest may be used if pre-operative reduction of $\mathrm{C} 1-\mathrm{C} 2$ subluxation is needed.

${ }^{3}$ The transoral approach, odontoid screw fixation, and minimally invasive techniques are possible alternatives, but they have not been advised for treatment of the pediatric population.

Figure 4: Algorithm for the management of Os odontoideum in children.

and Harms techniques provide relatively rigid fixation of the atlantoaxial joint compared to the earlier wiring techniques. As a result, external postoperative stabilization with a halo or Minerva vest is not required in a majority of cases. Nevertheless, a halo vest can be used as a model of preoperative traction in children to allow gradual reduction of $\mathrm{C} 1-\mathrm{C} 2$ subluxation and necessary alignment before proceeding to surgery. If the reduction is not successful, careful occipitocervical fusion can be advised.

In terms of real world screw-rod fixation experience, in 1999, Wang et al. reviewed 16 children with atlantoaxial instability, 4 of them had Os odontoideum [46]. They all underwent successful C1-C2 transarticular screw and posterior screw wiring and fusion. What is more interesting, they only used Miami-J collar and no other immobilization devices. All were fused at 3 months follow up [46]. In 2000, Brockmeyer et al. approached the $\mathrm{C} 1-\mathrm{C} 2$ fusion in 12 children with Os odontoideum using transarticular screw placement as well [40]. He concluded that this type of screw fixation is technically possible and favorable in the majority of pediatric population as long as patient anatomy allowed bilateral screw placement [40]. In 2009, Haque et al. reviewed 17 cases of children with upper cervical spine instability, 5 of them were diagnosed with Os odontoideum [47]. They were treated with transcarticular fusion of C1 lateral mass to $\mathrm{C} 2$ pars screw placement and all patients achieved fusion [47]. In 2014, Zhang et al. described 6 pediatric patients with Os odontoideum with the history of acute cervical cord trauma [48]. All patients underwent a successful rigid screw or steel wire fixation without any complications [48] (Table 1).
Other surgical techniques such as the transoral approach and odontoid screw fixation have been exploited, but without particular success. The transoral technique requires release of numerous anterior structures and is associated with significant morbidity [49]. The odontoid screw fixation is not recommended for this group of patients because of the pseudoarthrotic nature of Os odontoideum [49]. Posterior spinal cord decompression includes $\mathrm{C} 1$ laminoplasty and division of numerous soft tissue bands. Anterior spinal cord decompression is advised only if neurological deficits persist following posterior stabilization and are associated with ventral compression [48]. The most recent innovation in treatment of Os odontoideum is minimally invasive atlantoaxial fusion, which was first successfully performed and reported by Holly et al. in 2010 [50]. Among 6 adult patients, 1 had Os odontoideum and all were fused with no intraoperative complications [50-52]. Though this technique has not been used in children, it certainly could be considered as a potential surgical technique for treatment of Os odontoideum in the pediatric population.

Overall, the main challenge of treating Os odontoideum is its unpredictable natural history. Although conservative treatment might be a good option for some patients, those with significant atlantoaxial instability and myelopathy should undergo surgical treatment. Based on the literature and our experience, surgery is reserved for frank instability, uncontrolled pain, and neurological symptoms/signs. A summary of the real world experience can be found in Table 1 and a summary of the management algorithm in Figure 4.

\section{Discussion and Summary}

The diagnosis of Os odontoideum in children relies primarily on the clinical presentation. In order to confirm the findings, extensive radiologic evaluation is performed including anterioposterior, openmouth odontoid, and dynamic lateral flexion-extension $\mathrm{x}$-rays. The latter is only used in children with a stable cervical spine and/or in the absence of trauma to the cervical region. It is important to recognize that there are a number of other atlantoaxial pathologies that can mimic Os odontoideum, including ossiculum terminale, a nonfused synchodrosis, and odontoid fracture. All these etiologies can demonstrate similar neurological signs/symptoms and presentations on anterioposterior $\mathrm{X}$-ray imaging. Open-mouth odontoid films are the primary modality used to distinguish between Os odontoideum and type II odontoid fracture, as the normally shaped dens and a narrow gap between the base and the dens confirm the diagnosis of the odontoid fracture, whereas Os odontoineum usually appears as a smooth ossicle of variable shape separated from the base of the axis with a wide gap. In children under 3 years of age, the nonfused synchodrosis must be ruled out as well [3]. The significant movement of the ossicle along the anterior arch of $\mathrm{C} 1$ suggests a nonfused synchodrosis rather than Os odontoideum. Once all other differentials are ruled out and the diagnosis of Os odontoideum is confirmed, the next step in management is to identify the severity of the condition based on radiologic markers.

When the appropriate clinical and radiologic evaluation is complete, the next step is to decide which treatment option is appropriate for the patient. The caveat is that the management of Os odontoideum in children remains highly debated topic in neurosurgical practice due to the inability to predict the course of the disease given its variable nature. Conservative treatment is advised for patients with minimum or absent neurological symptoms. It is based on a "watch and wait" approach with long-term clinical and radiologic surveillance including yearly flexionextension lateral X-rays and MRI evaluation every 5 years [1]. If the child presents with significant atlantoaxial instability, neurological deficits, or myelopathy, then surgical treatment is recommended. The 
older wiring techniques such as atlantoaxial fixation with autologous bone fusion, Gallie, Kirschner and Brook's fusions are rarely used these days, but remain robust bailout procedures. They have mostly lost favor because they were found to be associated with a high risk of spinal cord injuries and all required long-term post-operative immobilization with a halo or Minerva brace, which predisposed patients to pin site infections and further morbidity. Today, the two main approaches for treatment of symptomatic Os odontoideum in children are transarticular C1-C2 screw fixation and C1-C2 rigid internal fixation with extension to the occiput in some cases. The former one is known for a $98 \%$ fusion rate [42], but is limited only to patients who have properly aligned atlantoaxial joints, no thoracic kyphotic deformity, and who have normal anatomy of the cervical spine and both vertebral arteries. In all other cases, the C1-C2 rigid internal fixation is advised. This technique allows placement of the screws in variable locations, which can take into account patients ' variations in anatomy of the cervical spine and vertebral arteries. It also provides a rigid construction eliminating the need for postoperative stabilization and assumes faster recovery. However, if a child requires a $\mathrm{C} 1-\mathrm{C} 2$ subluxation reduction preoperatively, a halo vest is advised to ensure a proper alignment before the surgical intervention. The transoral approach and odontoid screw fixation are not advised for the pediatric population. The minimally invasive technique has not been used in children yet, but has a great potential as an alternative treatment option as more clinical experience is gained.

\section{Conclusion}

Os odontoideum is a cervical spine anomaly that likely arises from a congenital, acquired, and/or multifactorial etiology. It can present in children as an incidental asymptomatic finding or as atlantoaxial instability with various neurological deficits. Multiple radiologic modalities can be used to confirm the diagnosis and to aid in identification of an appropriate route of treatment and management. In children in particular, the use of more precise modalities such as CT and MRI are advised due to the size limitations of the cervical region. Today, wiring surgical techniques have been substituted with the newer screw-rod fixation as these procedures eliminate the necessity for postoperative stabilization with a brace and have less surgical complications. In the end, Os odontoideum is a manageable condition in the pediatric population and the clinician must be astute in its diagnosis and treatment algorithms.

\section{References}

1. Arvin B Fournier-Gosselin MP, Fehlings MG (2010) Os odontoideum: etiology and surgical management. Neurosurgery 66: 22-31.

2. Perrini $P$, Montemurro N, lannelli $A$ (2013) The contribution of Carlo Giacomini (1840-1898): the limbus Giacomini and beyond. Neurosurgery 72: 475-481.

3. Vargas TM, Rybicki FJ, Ledbetter SM, MacKenzie JD (2005) Atlantoaxial instability associated with an orthotopic Os odontoideum: a multimodality imaging assessment. Emerg Radiol 11: 223-225.

4. Menezes AH (1999) Pathogenesis, dynamics, and management of Os odontoideum. Neurosurg Focus 6: e2.

5. Behari S, Jaiswal A, Srivastava A, Rajput D, Jain VK (2010) Os odontoideum with "free-floating" atlantal arch causing $\mathrm{C} 1-2$ anterolisthesis and retrolisthesis with cervicomedullary compression. Indian J Orthop 44: 417-423.

6. Cambell W (2007) Operative Orthopaedics. Pediatric cervical spine (11th edn), B.J.H. Canale S.T. Philadelphia, PA: Mosby.

7. Sankar WN, Wills BP, Dormans JP, Drummond DS (2006) Os odontoideum revisited: the case for a multifactorial etiology. Spine (Phila Pa 1976) 31: 979984.

8. Dai L Yuan W, Ni B, Jia L (2000) Os odontoideum: etiology, diagnosis, and management. Surg Neurol 53: 106-108.
9. McHugh BJ, Grant RA, Zupon AB, DiLuna ML (2012) Congenital Os odontoideum arising from the secondary ossification center without prior fracture. J Neurosurg Spine 17: 594-597.

10. Menezes $\mathrm{AH}$ (2008) Craniocervical developmental anatomy and its implications Childs Nerv Syst 24: 1109-1122.

11. Menezes AH, Fenoy KA (2009) Remnants of occipital vertebrae: proatlas segmentation abnormalities. Neurosurgery 64: 945-953.

12. wollin DG (1963) The Os Odontoideum. Separate Odontoid Process. J Bone Joint Surg Am 45: 1459-1471.

13. Morgan MK, Onofrio BM, Bender CE (1989) Familial os odontoideum. Case report. J Neurosurg 70: 636-639.

14. Kirlew KA, Hathout GM, Reiter SD, Gold RH (1993) Os odontoideum in identical twins: perspectives on etiology. Skeletal Radiol 22: 525-527.

15. Sherk HH, Dawoud S (1981) Congenital Os odontoideum with Klippel-Feil anomaly and fatal atlanto-axial instability. Report of a case. Spine (Phila Pa 1976) 6: 42-45.

16. Hukuda S, Ota H, Okabe N, Tazima K (1980) Traumatic atlantoaxial dislocation causing Os odontoideum in infants. Spine (Phila Pa 1976) 5: 207-210.

17. Kuhns LR Loder RT, Farley FA, Hensinger RN (1998) Nuchal cord changes in children with Os odontoideum: evidence for associated trauma. J Pediatr Orthop 18: 815-819.

18. Brecknell JE, Malham GM (2008) Os odontoideum: report of three cases. J Clin Neurosci 15: 295-301.

19. Verska JM, Anderson PA (1997) Os odontoideum. A case report of one identical twin. Spine (Phila Pa 1976) 22: 706-709.

20. Zygourakis CC, Cahill KS, Proctor MR (2011) Delayed development of Os odontoideum after traumatic cervical injury: support for a vascular etiology. J Neurosurg Pediatr 7: 201-204.

21. Schuler TC, Kurz L, Thompson DE, Zemenick G, Hensinger RN, et al. (1991) Natural history of Os odontoideum. J Pediatr Orthop 11: 222-225.

22. Watanabe M, Toyama Y, Fujimura $Y$ (1996) Atlantoaxial instability in Os odontoideum with myelopathy. Spine (Phila Pa 1976) 21: 1435-1439.

23. Klimo P, Jr Coon V, Brockmeyer D (2011) Incidental Os odontoideum: current management strategies. Neurosurg Focus 31: E10.

24. Hadley M (2002) Os Odontoideum. Neurosurgery 3: S148-155.

25. Fagan AB, Askin GN, Earwaker JW (2004) The jigsaw sign. A reliable indicator of congenital aetiology in Os odontoideum. Eur Spine J 13: 295-300.

26. Chang H, Park JB, Kim KW, Choi WS (2000) Retro-dental reactive lesions related to development of myelopathy in patients with atlantoaxial instability secondary to Os odontoideum. Spine (Phila Pa 1976) 25: 2777-2783.

27. Shirasaki N Okada K, Oka S, Hosono N, Yonenobu K, et al. (1991) Os odontoideum with posterior atlantoaxial instability. Spine (Phila Pa 1976) 16: 706-715.

28. Takakuwa T Hiroi S, Hasegawa H, Hurukawa K, Endo S, et al. (1994) Os odontoideum with vertebral artery occlusion. Spine (Phila Pa 1976) 19: 460462.

29. Matsui H, Imada K, Tsuji H (1997) Radiographic classification of Os odontoideum and its clinical significance. Spine (Phila Pa 1976) 22: 1706-1709.

30. http://emedicine.medscape.com/article/1265065-overview

31. Aksoy FG, Gomori JM (2000) Symptomatic cervical synovial cyst associated with an Os odontoideum diagnosed by magnetic resonance imaging: case report and review of the literature. Spine 25: 1300-1302.

32. Henderson S, Henderson D (2006) Os odontoideum with associated multidirectional atlantoaxial instability: imaging and clinical considerations. J Can Chiropr Assoc 50: 111-117.

33. Hensinger RN, Fielding JW, Hawkins RJ (1978) Congenital anomalies of the odontoid process. Orthop Clin North Am 9: 901-912.

34. Callahan RA, Lockwood R, Green B (1983) Modified Brooks fusion for an Os odontoideum associated with an incomplete posterior arch of the atlas. A case report. Spine (Phila Pa 1976) 8: 107-108.

35. Griswold DM, Albright JA, Schiffman E, Johnson R, Southwick W (1978) Atlanto-axial fusion for instability. J Bone Joint Surg Am 60: 285-292. 
36. Brooks AL, Jenkins EB (1978) Atlanto-axial arthrodesis by the wedge compression method. J Bone Joint Surg Am 60: 279-284.

37. Dyck $P$ (1978) Os odontoideum in children: neurological manifestations and surgical management. Neurosurgery 2: 93-99.

38. Smith MD, Phillips WA, Hensinger RN (1991) Fusion of the upper cervical spine in children and adolescents. An analysis of 17 patients. Spine (Phila Pa 1976) 16: 695-701.

39. Lowry DW, Pollack IF, Clyde B, Albright AL, Adelson PD (1997) Upper cervical spine fusion in the pediatric population. J Neurosurg 87: 671-676.

40. Brockmeyer DL, York JE, Apfelbaum RI (2000) Anatomical suitability of C1-2 transarticular screw placement in pediatric patients. J Neurosurg 92: 7-11.

41. Jeanneret B, Magerl F (1992) Primary posterior fusion $\mathrm{C} 1 / 2$ in odontoid fractures: indications, technique, and results of transarticular screw fixation. $J$ Spinal Disord 5: 464-475.

42. Farey ID Nadkarni S, Smith N (1999) Modified Gallie technique versus transarticular screw fixation in C1-C2 fusion. Clin Orthop Relat Res : 126-135.

43. Goel A Laheri V (1994) Plate and screw fixation for atlanto-axial subluxation. Acta Neurochir (Wien) 129: 47-53

44. Anderson RC Ragel BT, Mocco J, Bohman LE, Brockmeyer DL (2007) Selection of a rigid internal fixation construct for stabilization at the craniovertebral junction in pediatric patients. J Neurosurg 107: 36-42.
45. Hedequist DJ (2014) Modern posterior screw techniques in the pediatric cervical spine. World J Orthop 5: 94-99.

46. Wang J Vokshoor A, Kim S, Elton S, Kosnik E, et al. (1999) Pediatric atlantoaxial instability: management with screw fixation. Pediatr Neurosurg 30: 70-78.

47. Haque A Price AV, Sklar FH, Swift DM, Weprin BE, et al. (2009) Screw fixation of the upper cervical spine in the pediatric population. Clinical article. J Neurosurg Pediatr 3: 529-533.

48. Zhang Z, Wang H, Liu C (2015) Acute Traumatic Cervical Cord Injury in Pediatric Patients with Os Odontoideum: A Series of 6 Patients. World Neurosurg 83: 1180.

49. Menezes AH (2008) Craniovertebral junction database analysis: incidence, classification, presentation, and treatment algorithms. Childs Nerv Syst 24: 1101-1108.

50. Holly LT Isaacs RE, Frempong-Boadu AK (2010) Minimally invasive atlantoaxial fusion. Neurosurgery 66: 193-197.

51. Spierings EL, Braakman R (1982) The management of Os odontoideum Analysis of 37 cases. J Bone Joint Surg Br 64: 422-428.

52. Clements WD, Mezue W, Mathew B (1995) Os odontoideum--congenital or acquired?--that's not the question. Injury 26: 640-642. 